\title{
Synthesis, Structure and Characterization of Adducts of $O$-Propyldithiocarbonates with Substituted Pyridines
}

\author{
INDERJEET KOUR*, GURPREET KOUR and RENU SACHAR
}

Department of Chemistry, University of Jammu, Jammu Tawi - 180006, India

inderjeet100kour@gmail.com

Received 10 January 2014 / Accepted 24 January 2014

\begin{abstract}
A series of six coordinated $\mathrm{Ni}(\mathrm{II})$ complexes with general formula $\left[\mathrm{Ni}\left(\mathrm{C}_{5} \mathrm{H}_{4} \mathrm{NCl}\right)_{2}\right.$ $\left.\left(\mathrm{S}_{2} \mathrm{COC}_{3} \mathrm{H}_{7}\right)_{2}\right]$ was synthesized and characterized. All the complexes have 1:2 stoichiometry, are non ionic and paramagnetic in nature. TGA-DTA studies show the formation of $\mathrm{NiS}$ as the stable end product of the decomposition. One of the adducts bis(O-propyldithiocarbonato)bis (3-chloropyridine) nickel(II) crystallizes in the monoclinic space group $\mathrm{P} 21 / \mathrm{c}$. The $\mathrm{Ni}^{2+}$ ion is in an octahedral coordination environment formed by an $\mathrm{N}_{2} \mathrm{~S}_{4}$ donor set, defined by two chelating dithiocarbonate anions as well as two 3-chloropyridine ligands with the $\mathrm{Ni}^{2+}$ ion located at the inversion centre. The packing of layers of molecules is stabilized by weak $\pi-\pi$ and $\mathrm{C}-\mathrm{H} \cdots \pi$ interactions. The asymmetric unit comprises of half molecule and Nickel(II) cation lies on an inversion centre.
\end{abstract}

Keywords: Adducts, Xanthates (dithiocarbonates), Octahedrally coordinated, Direct methods, Crystal structure, $\pi-\pi$ and $\mathrm{C}-\mathrm{H} \cdots \pi$ interaction

\section{Introduction}

The chemistry of transition metal $O$-alkyldithiocrbonates, named xanthate, has developed rapidly and many complexes have been prepared and investigated during the last several decades ${ }^{1}$. The presence of soft donor group on xanthates i.e. 'S', makes them highly reactive towards several metal atoms. Xanthates are known to form a variety of complexes with most of the transition and non-transition metals ${ }^{2-3}$. Transition metal xanthates and their adducts with variety of Lewis bases such as amine, imine and phosphine are extensively investigated not only for their wide applications in various fields but also for coordination variability of xanthate anions, which can act as mono-or bidentate ligands or may lie outside the coordination sphere of central atom ${ }^{4-5}$. Several bivalent metal atoms are known to form complexes with xanthate as a ligand. These metal complexes are usually unsaturated and thus they can react easily with monodentate (in the molar ratio 1:2) or bidentate (In the molar ratio $1: 1)$ nitrogen donor ligands to form octahedral complexes ${ }^{6-7}$. Although nickel(II) xanthate complexes have been known since the early 1800's they are still extensively studied for their possible applications in several branches of industry, as fungicides, insecticides, antioxidants, etc $^{8-9}$. In a sequence to our systematic study on the synthesis and characterization of xanthates of $\mathrm{Ni}$ (II) with heterocyclic amines, in this article, we report the synthesis of a new series of 
complexes of $\mathrm{Ni}(\mathrm{II})$ propylxanthate with chloropyridines. The structure of the one of the representing complexes was established through x-ray crystallography. Various physicochemical studies such as IR, UV-Vis and TGA/DTA spectra of the complexes were also determined which also coincides with the results obtained through crystal study.

\section{Experimental}

The Elemental analysis was performed on elemental analyzer (Elemental vario EL III, carlo Erba 1108). Molar conductance was measured in DMF using CC 601 Conductivity Bridge. The IR spectra was recorded on a Infrared spectrophotometer (Perkin Elmer FT-IR) over the region 4000-400 $\mathrm{cm}^{-1}$ using $\mathrm{KBr}$ pellets. The electronic absorption spectra were recorded on Systronic $119 \mathrm{UV}-\mathrm{V}$ is spectrophotometer. The magnetic susceptibility was measured at room temperature by Guoy's method using $\mathrm{Hg}\left[\mathrm{Co}(\mathrm{CNS})_{4}\right]$ as calibrant. Corrections for diamagnetic constant were measured using Pascal's constant. Thermo gravimetric analysis (TGA) of the present complex was determined on Linseis STA-PT-1000 at $10{ }^{\circ} \mathrm{C} / \mathrm{min}$

\section{Synthesis of the starting material}

The potassium salt of $O$-propyldithiocarbonate was prepared by the standard published method $^{10}$. Potassium hydroxide pellets $42 \mathrm{~g}(0.75 \mathrm{~mole})$ were dissolved in $n$-propylalochol 156 $\mathrm{g}(194 \mathrm{ml}, 2.6 \mathrm{~mol})$ in a round bottom flask and refluxed for one hour. The reaction mixture was allowed to cool and the solution was decanted off from the residual solid into a beaker. To the resulting solution, carbon disulfide $57 \mathrm{~g}(45 \mathrm{~mL}, 0.75 \mathrm{~mol})$ was added drop wise and with constant stirring. The reaction mixture was allowed to cool in an ice bath and the resulting solid mass was filtered on a sintered glass funnel at the pump, washed it with three $25 \mathrm{~mL}$ portions of ether, dried in vacuum desiccators and recrystallized from absolute ethanol.

\section{Preparation of bis(O-propylxanthato)nickel(II), $\left[\mathrm{Ni}\left(\mathrm{S}_{2} \mathrm{CoC}_{3} \mathrm{H}_{7}\right)_{2}\right]$}

The complex $\left[\mathrm{Ni}\left(\mathrm{S}_{2} \mathrm{CoC}_{3} \mathrm{H}_{7}\right)_{2}\right]$ was prepared by mixing and constant stirring of an aqueous solution of nickel(II) chloride (2.37 g. 0.01 moles) and potassium salt of propylxanthate (3.48 g. 0.02 moles). Green coloured precipitates were obtained which were filtered and dried in vacuum desiccators.

\section{Preparation of adducts of bis(O-propylxanthato)nickel(II) with substituted pyridine}

The 1:2 adduct of nickel(II)xanthate was prepared by dissolving $\left[\mathrm{Ni}\left(\mathrm{S}_{2} \mathrm{CoC}_{3} \mathrm{H}_{7}\right)_{2}\right](0.85 \mathrm{~g}$, 0.0026 moles) in acetone $(50-60 \mathrm{~mL})$. To the brown coloured solution so obtained substituted pyridine (2-, 3-, 4-chloropyridine) ( $0.56 \mathrm{~g}, 0.0052 \mathrm{moles})$ was added slowly with constant stirring over a period of $30 \mathrm{~min}$. The colour of the mixture slowly changes to green showing the coordination of ligand with metal. The contents of the reaction mixture were then filtered and allowed to stand for 20-24 hours, depositing shining green crystalline solids which were then washed with the solvent used in their preparation and dried over calcium chloride at room temperature. Adducts thus obtained were recrystallised from acetone.

\section{$X$-ray crystal structure}

Detailed structural information on the conformation of the molecule in the crystalline state was obtained by employing x-ray crystallographic techniques. A dark green blocked-shaped single crystal of the title compound measuring $0.30 \times 0.20 \times 0.20 \mathrm{~mm}$ was picked up for $\mathrm{x}$-ray intensity data collection on a CCD area-detector diffractometer (X'calibur system-Oxford diffraction make, U.K.) which is equipped with graphite monochromated MoK $\alpha$ radiation $(\lambda=0.71073 \AA)$. A total number 18668 of reflections were collected of which 2004 reflections were treated as observed $(\mathrm{I}>2 \sigma(\mathrm{I}))$. Data were reduced using Crysalis RED software. ${ }^{11}$ Data were corrected for Lorentz and polarization and absorption factors. 
The structure was solved by direct methods using SHELXS97 and refined ${ }^{12}$ by SHELXL97. All the hydrogen atoms were located from a difference electron density map and their positional and isotropic thermal parameters were included in the refinement. The final refinement cycle yielded an R- factor of 0.0230 and $w R\left(F^{2}\right)=0.0570$ for the observed data. The residual electron density ranges from $-246<\Delta \rho<287 \mathrm{e} \AA^{-3}$. The CIF for this structure has been deposited at Cambridge Crystal Data Centre.(CCDC number 895314).

\section{Results and Discussion}

The reaction product of bis(O-propylxanthato)nickel(II) with chloropyridines are bright green coloured crystalline solids which are soluble in acetone, chloroform, DMF, DMSO. The chemical composition of the complexes prepared and the results of various physic chemical studies are summarized in Table 1 . On the basis of elemental analysis the adducts isolated having 1:2 stichiometry and are assigned formula $\left[\mathrm{Ni}_{(}\left(\mathrm{S}_{2} \mathrm{CoC}_{3} \mathrm{H}_{7}\right)_{2}\right] \mathrm{L}_{2}$ where $\mathrm{L}=2$ chloropyridine, 3-chloropyridine, 4-chloropyridine.

\section{Conductance and Magnetic measurements}

The molar conductivity value calculated from the conductivity measurements of millimolar solution of the complexes in DMF, supports the neutral and non-ionic nature of the complexes ${ }^{13-14}$. The effective room temperature magnetic moment of the complexes prepared was found to be in the range of 3.00-3.25 B.M. which is in agreement with magnetic moment values observed for paramagnetic octahedral complexes of nickel(II) ${ }^{15}$ (Table 1).

Table 1. Physical and analytical data of bis(O-propyldithiocarbonato)bis(chloropyridine) nickel(II) with nitrogen donor

\begin{tabular}{|c|c|c|c|c|c|c|c|c|c|c|}
\hline \multirow{2}{*}{ Complex } & \multirow{2}{*}{$\begin{array}{l}0 \\
0 \\
\dot{\Sigma}\end{array}$} & \multicolumn{4}{|c|}{$\%$ Found } & \multicolumn{4}{|c|}{$\%$ Calculated } & \multirow{2}{*}{$\begin{array}{c}\text { Molar } \\
\text { conductance } \\
\mu_{\text {eff }} \\
\mathrm{ohm}^{-1} \mathrm{~cm}^{2} \\
\mathrm{~mol}^{-1}{ }_{(\mathrm{BM})}\end{array}$} \\
\hline & & $\mathrm{C}$ & $\mathrm{H}$ & $\mathrm{N}$ & $\mathrm{S}$ & $\mathrm{C}$ & $\mathrm{H}$ & $\mathrm{N}$ & $\mathrm{S}$ & \\
\hline $\begin{array}{l}\mathrm{Ni}\left(\mathrm{S}_{2} \mathrm{COCH}_{2} \mathrm{CH}_{2}\right. \\
\left.\mathrm{CH}_{3}\right)_{2} \\
(\text { 2-Chloropyridine })_{2}\end{array}$ & 81.8 & 44.39 & 5.27 & 5.43 & 24.11 & 45.73 & 5.83 & 5.63 & 24.45 & 58.91 \\
\hline $\begin{array}{l}\mathrm{Ni}\left(\mathrm{S}_{2} \mathrm{COCH}_{2} \mathrm{CH}_{2}\right) \\
\left.\mathrm{CH}_{3}\right)_{2} \\
\text { (3-Chloropyridine })_{2}\end{array}$ & 83 & 45.39 & 5.29 & 5.57 & 24.21 & 45.73 & 5.85 & 5.63 & 24.45 & 59.28 \\
\hline $\begin{array}{l}\mathrm{Ni}\left(\mathrm{S}_{2} \mathrm{COCH}_{2} \mathrm{CH}_{2}\right. \\
\left.\mathrm{CH}_{3}\right)_{2} \\
\text { (4-Chloropyridine })_{2}\end{array}$ & 82.7 & 45.28 & 5.47 & 5.49 & 24.38 & 45.73 & 5.85 & 5.63 & 24.45 & 60.03 \\
\hline
\end{tabular}

\section{IR and electronic spectra}

The infrared spectrum of the complexes $\left[\mathrm{Ni}\left(\mathrm{S}_{2} \mathrm{CoC}_{3} \mathrm{H}_{7}\right)_{2} \mathrm{~L}_{2}\right]$ exhibits characteristic bands for xanthato ligand $^{16}$ in the range of 1197-1201 and 1110-1130 $\mathrm{cm}^{-1}$ which are attributed to the stretching vibrations of the C-O-C group, while the bands at $1030-1137 \mathrm{~cm}^{-1}$ belong to $v(\mathrm{C}-\mathrm{S})$ vibrations ${ }^{17}$. The bands at $1460-1580$ belong to ring stretching vibrations of coordinated chloropyridine ligand. The Electronic absorption spectra show absorption bands $v_{1}\left(15300 \mathrm{~cm}^{-1}\right)$, $v_{2}\left(19800 \mathrm{~cm}^{-1}\right)$ and $v_{3}\left(23500 \mathrm{~cm}^{-1}\right)$, which probably corresponds to the d-d transitions ${ }^{3} \mathrm{~A}_{2} \mathrm{~g}$ ${ }^{3} \mathrm{~T}_{2} \mathrm{~g}(\mathrm{~F}),{ }^{3} \mathrm{~A}_{2} \mathrm{~g}{ }^{3} \mathrm{~T}_{1} \mathrm{~g}(\mathrm{~F})$ and ${ }^{3} \mathrm{~A}_{2} \mathrm{~g}{ }^{3} \mathrm{~T}_{1} \mathrm{~g}(\mathrm{P})$ respectively. Appearance of these three broad bands along with shoulders shows that adducts are having trans octahedral geometry around nickel(II) metal ion. The intense absorption maxima $29000 \mathrm{~cm}^{-1}$ are related to the CT or $\pi-\pi^{*}$ transitions (Table 2). 
Table 2. Selected IR spectral bands and electronic spectral data of the complex

\begin{tabular}{|c|c|c|c|c|c|c|c|c|}
\hline \multirow{2}{*}{ Compound } & \multicolumn{4}{|c|}{ IR spectral data } & \multicolumn{4}{|c|}{ Electronic spectral data, $\mathrm{cm}^{-1}$} \\
\hline & $v_{\mathrm{as}}(\mathrm{C}-\mathrm{O}-\mathrm{C})$ & $v_{\mathrm{s}}(\mathrm{C}-\mathrm{O}-\mathrm{C})$ & $v(\mathrm{C}=\mathrm{S})$ & $v(\mathrm{C}=\mathrm{N})$ & $v(\mathrm{C}=\mathrm{C})$ & $v_{1}$ & $v_{2}$ & $v_{3}$ \\
\hline $\mathrm{Ji}\left(\mathrm{S}_{2} \mathrm{COCH}\right.$ & 1199 & 1111 & 1032 & 1577 & 1448 & 15287 & 19786 & 23488 \\
\hline $\mathrm{Ni}\left(\mathrm{S}_{2} \mathrm{COCH}_{2} \mathrm{CH}_{2} \mathrm{CH}_{3}\right)_{2}$ & 1200 & & & & 1456 & 15300 & 19800 & 23500 \\
\hline $\begin{array}{l}\mathrm{Ni}\left(\mathrm{S}_{2} \mathrm{COCH}_{2} \mathrm{CH}_{2} \mathrm{CH}_{3}\right)_{2} \\
\text { (4-Chloropyridine })_{2}\end{array}$ & & & 1028 & 1580 & 1450 & 15293 & 19784 & 23492 \\
\hline
\end{tabular}

\section{TGA/DTA studies}

The TGA/DTA studies of the complexes prepared were carried out from 20 to $750{ }^{\circ} \mathrm{C}$ at the rate of $10{ }^{\circ} \mathrm{C} / \mathrm{min}$. The TGA curve of one of the representing complexes, i.e. bis $(O$-propylxanthato) nickel(II) with 3-chloropyridine is shown in the Figure 1. The complex first decomposes at a $126.2{ }^{\circ} \mathrm{C}$ showing the loss of an alkyl moiety (weight loss found $=4.7 \%$, calculated $=4.5 \%$ ). The DTA curve shows a sharp endothermic peak below $100{ }^{\circ} \mathrm{C}$ indicating that the water molecules are present outside the coordination sphere. A major loss occurs at $187.3^{\circ} \mathrm{C}$ which corresponds to the loss of xanthato group (weight loss $=53.3 \%$ calculated $=49.5 \%$ ). This loss has also been supported by sharp exothermic curve at the same temperature. With the rise in temperature, the weight loss was found to be $88.9 \%$ at $678.4{ }^{\circ} \mathrm{C}$ indicating the loss of both the molecules of 3-chloropyridine (weight loss found $=88.9 \%$, calculated $=88.3 \%$ ). It has also been supported by the DTA curve. The weight loss continues at a slower rate up to $750{ }^{\circ} \mathrm{C}$ leaving behind stable NiS (Figure 1).

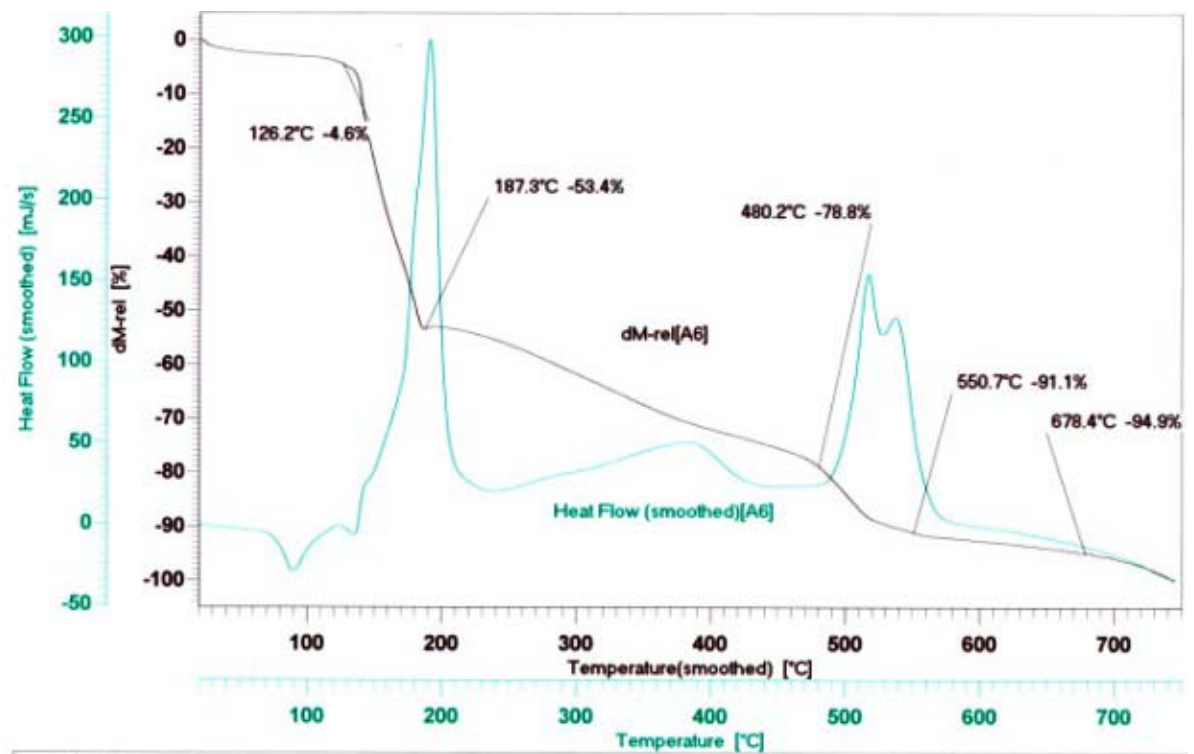

Figure 1. The TGA curve of one of the representing complex, i.e. bis(O-propylxanthato) nickel(II) with 3-chloropyridine

\section{Description of the crystal structure}

The crystallography data for bis(O-propylxanthato)bis(3chloropyridine)nicke(II) are presented in Table 3. Selected bond distances and bond angles for non- hydrogen atoms are 
listed in Table 4. A general view of the molecule indicating atom numbering scheme is shown in Figure 2. ORTEP-3 software ${ }^{18}$ was used for making the thermal ellipsoids (Figure 3). The geometry of the molecule was calculated using $P L A T O N^{19}$ and PARST $^{20}$ software.

Table 3. Crystallographic data for the title complex

\begin{tabular}{|c|c|}
\hline CCDC number & 895314 \\
\hline Empirical formula & $\mathrm{C}_{18} \mathrm{H}_{22} \mathrm{C}_{12} \mathrm{~N}_{2} \mathrm{Ni} \mathrm{O}_{2} \mathrm{~S}_{4}$ \\
\hline Formula weight & 556.23 \\
\hline Temperature (K) & $293(2)$ \\
\hline Shape & Block shaped \\
\hline Color & Green \\
\hline Crystal system & Monoclinic \\
\hline Space group & $\mathrm{P} 2_{1} / \mathrm{c}$ \\
\hline \multicolumn{2}{|l|}{ Unit cell dimensions $\left(\AA,^{\circ}\right)$} \\
\hline $\mathrm{a}$ & $9.4079(1)$ \\
\hline $\mathrm{b}$ & $10.7323(2)$ \\
\hline $\mathrm{c}$ & $11.7498(2)$ \\
\hline$\alpha$ & 90.00 \\
\hline$\beta$ & $96.443(1)^{\mathrm{o}}$ \\
\hline$\gamma$ & 90.00 \\
\hline Volume $\left(\AA^{3}\right), \mathrm{Z}$ & $1178.87(3), 2$ \\
\hline Dimension $\left(\mathrm{mm}^{3}\right)$ & $0.30 \times 0.20 \times 0.20$ \\
\hline $\mathrm{D}_{\mathrm{c}}\left(\mathrm{gcm}^{-3}\right)$ & 1.567 \\
\hline$\mu\left(\mathrm{mm}^{-1}\right)$ & 1.422 \\
\hline $\mathrm{F}(000)$ & 572 \\
\hline $2 \theta$ range for data collection $\left(^{\circ}\right)$ & $3.49-26.00$ \\
\hline \multirow[t]{3}{*}{ Limiting indices } & $-11<\mathrm{h}<11$ \\
\hline & $-13<\mathrm{k}<13$ \\
\hline & $-14<1<14$ \\
\hline Reflection collected & 30854 \\
\hline Independent reflection & 2315 \\
\hline Goodness-of-fit on $\mathrm{F}^{2}$ & 1.086 \\
\hline Data/restraint/parameter & $2315 / 0 / 135$ \\
\hline Final R Indices $[\mathrm{I}>2 \sigma(\mathrm{I})]$ & 0.0230 \\
\hline $\mathrm{R}$ indices (all data) & 0.0283 \\
\hline 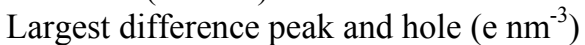 & 287 and -246 \\
\hline
\end{tabular}

Table 4 . Selected bond distances $(\AA)$ and bond angles $\left(^{\circ}\right)$

\begin{tabular}{llll}
\hline Bond Distances & & & \\
\hline Ni1-N1 & $2.127(1)$ & Ni1-S2 & $2.421(4)$ \\
Ni1-S3 & $2.461(5)$ & S2-C7 & $1.688(2)$ \\
S3-C7 & $1.688(2)$ & C7-O8 & $1.328(2)$ \\
O8-C9 & $1.450(3)$ & C5-CL4 & $1.734(2)$ \\
1.734(2) & $1.336(2)$ & N1-C6 & $1.335(2)$ \\
Bond Angles & & & \\
N1-Ni1-S2 & $90.06(4)$ & N1-Ni1-S3 & $89.46(4)$ \\
S2-Ni1-S3 & $73.98(2)$ & C7-S2-Ni1 & $83.14(6)$ \\
83.14(6) & $81.90(7)$ & O8-C7-S2 & $115.83(1)$ \\
O8-C7-S3 & $123.24(2)$ & S2-C7-S3 & $120.93(1)$ \\
\hline \multicolumn{5}{r}{}
\end{tabular}




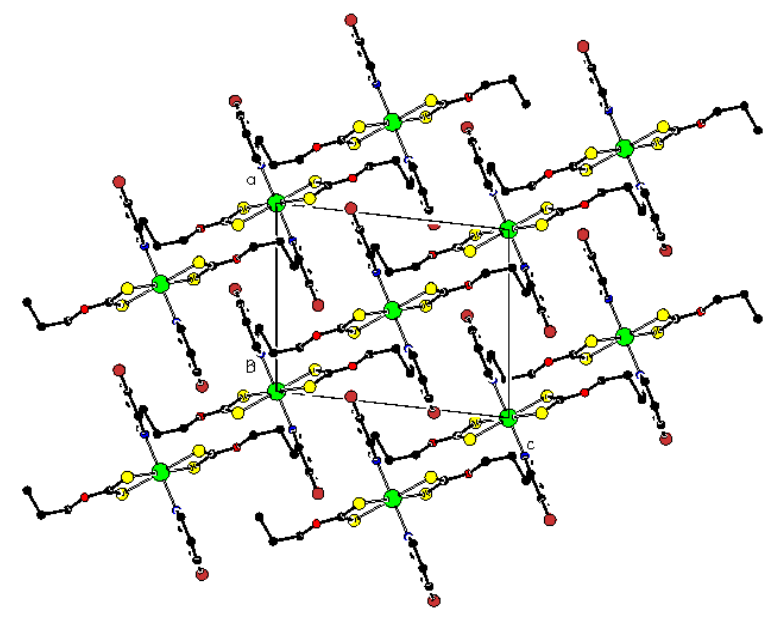

Figure 2. Packing arrangement viewed along one of the axis of the unit cell

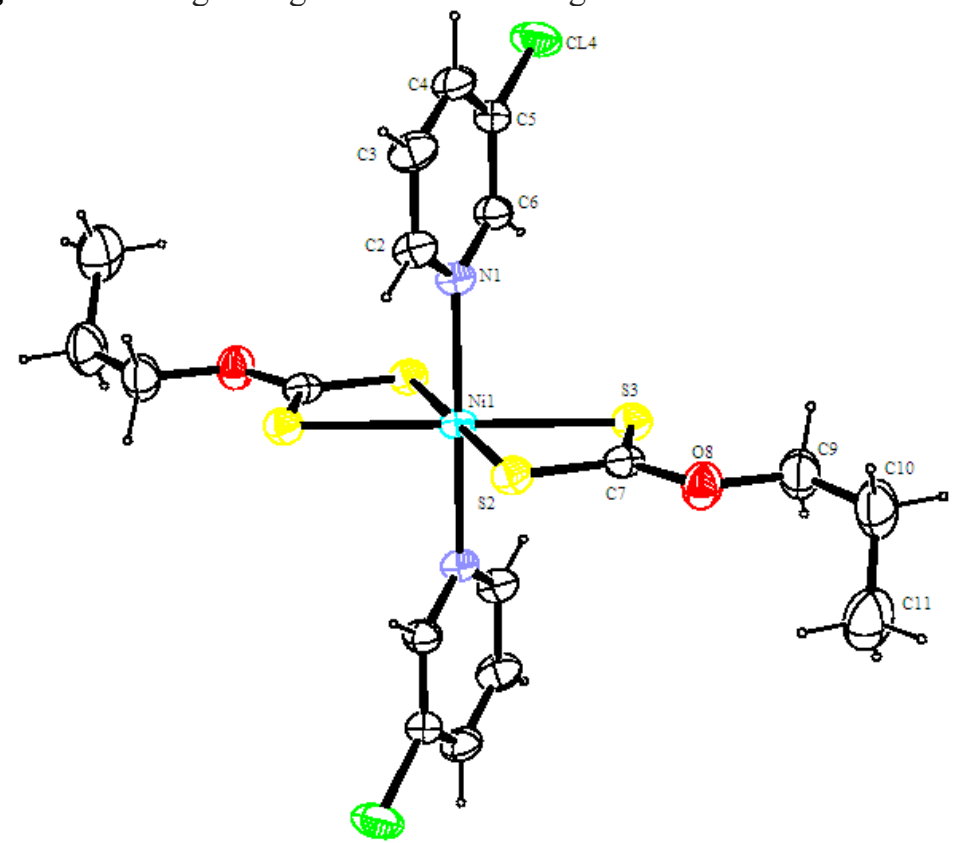

Figure 3. ORTEP view of the molecule with displacement ellipsoids drawn at the $50 \%$ probability level. $\mathrm{H}$ atoms are shown as small spheres of arbitrary radii

The asymmetric unit comprises of half molecule and nickel(II) cation lies on an inversion centre. The $\mathrm{Ni}(\mathrm{II})$ atom is coordinated by a distorted octahedral arrangement of four sulphur atom from two chelating xanthate ligands and two nitrogen atoms from two chloropyridines ligands. The Ni1-N1 bond length is 2.127(1) $\AA$. The Ni-S bond lengths involving the xanthate ligands are 2.421(4) $\AA$ for Ni1-S2 and 2.461(5) $\AA$ for Ni1-S3. The bond angles in the pyridine ring vary from $117.7(2)$ to $122.8(2)^{\circ}$, the average value being $119.9(9)^{\circ}$ and these values of bond angles and bond distances are in good agreement with those reported for other analogous Ni-dithiocarbonato complexes ${ }^{21,22}$. 
The C-S bond lengths involving the xanthate ligands are: S2-C7 $=1.688(2)$ and S3-C7 $=1.688(2) \AA$. These values are same and they show double bond character that is due to the delocalization over the two C-S bonds ${ }^{23}$. The plane formed by two sulfur, a nickel and a carbon atoms (Ni1, S2, C7, S3) is planer and the dihedral angle between this plane and the plane of cyanopyridine ring is $89.25(4)^{\circ}$ meaning thereby both these planes are held almost perpendicular to each other. The O8-C7 bond distance $[1.328(2) \AA]$ is shorter than O8-C9 $[1.450(3) \AA]$ as a consequence of the hybridization of the carbon atom. The short value of bond distance for $\mathrm{O} 4-\mathrm{C} 3$ is consistent with a significant contribution of the resonance form of the xanthate anion that features a formal $\mathrm{C}=\mathrm{O}$ and a negative charge on each of $\mathrm{S}$ atom ${ }^{24}$.

The packing of the molecule within the unit cell viewed down the $\mathrm{x}$-axis is shown in the Figure 2. Molecules in the crystal are packed together to form layers, which appear to be extending diagonally along the ac plane. The nickel atom of the molecule is located at each corner as well as at the centre of unit cell.

\section{Conclusion}

The various investigations like analytical data, conductivity measurement, spectral and magnetic studies done on the adducts reported in this paper reveal that these adducts are octahedral, non-electrolytic and paramagnetic in nature. In the x-ray crystal structure of bis(O-propyldithiocarbonato)bis(3-chloro pyridine)nickel(II) the two pyridine rings are coplanar and are held almost perpendicular to the dithiocarbonato groups.

\section{Appendix}

Supplementary data

Crystallographic data for the structure reported in this paper has been collected from Department of Physics, University of Jammu, Jammu, India.

\section{Acknowledgement}

The authors greatly acknowledge the scientific support from the Post Graduate Department of Chemistry, University of Jammu, Jammu and Kashmir. This paper is a part of the research work entitled, "Synthesis and Characterization of Xanthates and their Adducts with Nitrogen and Oxygen donors".

\section{References}

1. Zeise W C, Rec Mem Acad R Sci Copenhagen, 1815, 1, 1

2. Winter G, Rev Inorg Chem., 1980, 2, 253-342,

3. Tiekink E R T and Winter G, Rev Inorg Chem., 1992, 12, 183

4. Travnicek Z, Malon M and Sinetar Z, Trans Met Chem., 1999, 24(1), 38-41; DOI:10.1023/A:1006987319004

5. Ballester L, Gutierrez A and Perpinan M F, Motekaitis R J, Murase I and Martell A E, Polyhedron, 1996, 7(11), 1103-1107; DOI:10.1016/0020-1650(71)80101-0

6. Abramov A and Forssberg K S E, Miner Process Extr Metal Rev., 2005, 26(2), 77-143.

7. Reddy P and Ch Rangamannar B, J Radioanal Nucl Chem., 1996, 9, 213.

8. Wolf N and Roundhill D M, Polyhedron, 1994, 13(19), 2801-2808; DOI:10.1016/S0277-5387(00)83440-3

9. Yam V W W, Lau V C Y and Cheung K K,.J Chem Soc., Chem Commun., 1995, 9, 259-261; DOI:10.1039/C39950000259

10. Macgregov M J, Hogarth G, Thompson A L and Wiltonn Ely J D E T, J Organometallics, 2009, 28, 197. 
11. Oxford Diffraction, CrysAlis PRO Oxford Diffraction Ltd, 2010 Yarnton, England.

12. Sheldrick G M, Acta Cryst., 2008, A64, 112-122; DOI:10.1107/S0108767307043930

13. Martin R L and Whitley A, J Chem Soc., 1958, 1394-1402; DOI:10.1039/JR9580001394

14. Geary W J, Coord Chem Rev., 1971, 7(1), 81-122; DOI:10.1016/S0010-8545(00)80009-0

15. Basolo F and Matousch W R, J Am Chem Soc., 1953, 75(22), 5663-5666; DOI:10.1021/ja01118a057

16. Coucouvanis D and Fackler J P, Prog Inorg Chem., 1967, 6, 2047-2053; .

17. Zagal J and Costamangna J A, Inorg Nucl Chem Lett., 1977, 13(9), 411-416; DOI:10.1016/0020-1650(77)80030-5

18. Farrugia L J, J Appl Cryst., 1997, 30(5-1), 565; DOI:10.1107/S0021889897003117

19. Spek A L, Acta Cryst., 2009, D65(2), 148-155; http://dx.doi.org/10.1107/S090744490804362X

20. Nardelli M, J Appl Cryst., 1995, 28(5), 659; DOI:10.1107/S0021889895007138

21. Kapoor S, Sachar R, Singh K, Gupta V K and Rajnikant V, J Chem Crystallogr. 2012, 42(3), 222-226; DOI:10.1007/s10870-011-0228-y

22. Kapoor S, Kour R, Sachar R, Kant R, Gupta V K and Kapoor K, Acta Cryst., 2012, E68, m58; DOI:10.1107/S1600536811053475

23. Jiang X H, Zhang W G, Zhong Y and Wang S L, Molecules., 2002, 7(7), 549-553; DOI:10.3390/70700549

24. Alam N, Ehsan M A, Zeller M, Mazhar M and Arifin Z, Acta Cryst., 2011, E67, m1064; DOI:10.1107/S1600536811026523 